\title{
Obreros y estudiantes, ¿unidos y adelante? Los estudiantes de la Universidad de Buenos Aires frente al movimiento obrero bajo la "Revolución Argentina", 1966-1973
}

\author{
Juan Sebastián Califa \\ Conicet - Instituto Ravignani - Facultad de Ciencias Sociales (UBA) - jscalifa@hotmail.com
}

\section{Introducción}

La relación entre el movimiento obrero y el movimiento estudiantil durante la década de 1960 ha sido objeto de numerosas conjeturas. Se ha sostenido que los estudiantes como parte de la intelectualidad no comprendian al peronismo y, por ello, a los trabajadores (Terán, 2013) y que más allá de su radicalismo verbal la joven militancia universitaria mantenía prejuicios enraizados en su clase de origen -clase media o pequeño-burguesia- que le impedian concretar la unidad obrera (Graciarena, 1971; Sigal, 1991).Este tipo de enunciados se encuentra en línea con el discurso que el peronismo levantó en esos años, acusando a la universidad de haberse convertido en una "isla democrática", como un modo de legitimar su accionar (Barletta, 2002). En un trabajo reciente he discutido este tipo de afirmaciones (Califa, 2014a). Sea como sea, todos estamos de acuerdo en el hito que significó el golpe de Estado de 1966, siendo los siete años comprendidos por la autoproclamada "Revolución Argentina" un período de agudas transformaciones en esa relación obrero-estudiantil. Pero, con todo, todavia es poco lo que se sabe. La respuesta, aunque sea parcial, a una serie de interrogantes harian posible avanzar en el conocimiento específico: ¿qué dimensión implicó este cambio? ¿Los trabajadores o su dirigencia sindical, o determinados sectores, estaban interesados en el movimiento estudiantil? ¿En qué términos y buscando qué fines fue posible converger? ¿Hubo diferentes etapas en este proceso? ¿Cómo reaccionaron los distintos grupos estudiantiles y el alumnado en general?

El aporte de estas páginas apunta precisamente a explicar las particularidades del vínculo obrero-estudiantil en Buenos Aires, analizando lo sucedido en la UBA, durante la autodenominada "Revolución 
Argentina" entre 1966 y 1973. Guiado por las anteriores preguntas, $\mathrm{y}$ atendiendo a la heterogeneidad del caso, el principal aporte de este artículo consistirá en proponer una periodización que haga observables las transformaciones del vínculo aludido. Para ello se recurrirá a una amplia bibliografia, diversos archivos, revistas y finalmente diarios de la época que se recuperan de una base de datos (Base de Datos Bonavena, de aquí en más BDB) de comprobada fiabilidad y representatividad. ${ }^{1}$ La propuesta de abordaje empírico sigue una tradición marxista de observación social, que en la Argentina fue recobrada por la producción del extinto CICSO, la cual privilegia el abordaje de los enfrentamientos sociales para descifrar la evolución de la sociedad y el derrotero de los sujetos implicados.

\section{Golpe, derrota y separación obrero-estudiantil}

El 28 de junio de 1966 asumía la presidencia tras el golpe de Estado el general retirado Juan Carlos Onganía. En su asunción se hizo presente un amplio abanico de personalidades que incluía figuras destacadas del empresariado, la política y el gremialismo, como el líder de la CGT Augusto Vandor. La "Revolución Argentina" iniciaba así la "modernización autoritaria", etapa donde el "tiempo político" quedaría supeditado, según expresó Onganía, a los objetivos trazados para el "tiempo económico" (O’Donnell, 2009).

En el terreno universitario el impacto del golpe fue enorme. El derrotero de activación política estudiantil precedente alarmaba al nuevo Ejecutivo (Califa, 2014a). Finalmente, el 29 de julio de 1966 el DecretoLey 16.912 dispuso la intervención de las universidades nacionales una vez confiada la Subsecretaría de Educación al abogado católico Carlos María Gelly y Obes, cartera dependiente, según la nueva estructura administrativa, del Ministerio del Interior presidido por el cursillista cordobés Enrique Martínez Paz.

La intervención atacaba la democracia interna de las universidades públicas al desconocerles legitimidad e injerencia a sus órganos de gobierno, con destacada participación estudiantil. Se trataba, en síntesis, de liquidar la institucionalidad que había empezado a construir la Reforma Universitaria iniciada en Córdoba durante 1918 y que el

1. Esta base reconstruye día a día las luchas del movimiento estudiantil argentino entre los golpes de Estado de 1966 y 1976. Para la Capital Federal fueron relevados los diarios Crónica, Clarín, La Nación, La Opinión y La Prensa, aunque el modo de registro no aclara de qué periódico se extrae cada información. Cuando se necesite ampliar algún hecho, se recurrirá directamente al diario que permita explayarse en el mismo. La base puede consultarse en el área de Conflicto Social del Instituto de Investigaciones "Gino Germani" de la UBA. 
cuerpo universitario, tras una historia de avances y reveses permanentes, con una intervención crucial del movimiento estudiantil que asumía ese legado, había profundizado diez años atrás. La intervención tuvo su epicentro en la Facultad de Ciencias Exactas y Naturales de la UBA durante la llamada "Noche de los Bastones Largos". En esa jornada, estudiantes y docentes debieron soportar en soledad la represión policial que detuvo alrededor de 150 personas (Diaz de Guijarro et al., 2015: 234) y un número menor en Filosofia y Letras y en Arquitectura (Morero et al., 1996).

Frente a ello, la dirigencia sindical peronista mayoritaria prefirió no inmiscuirse (Selser, 1986: 136). ¿Fue una venganza hacia los estudiantes por profesar lealtades políticas reñidas con la suya? Así razonaba José Taccone, lider de la Federación de Luz y Fuerza, quien les espetó a un grupo de estudiantes que

su sindicato no tenía ningún inconveniente en repudiar los excesos policiales que culminaron con el apaleamiento de estudiantes en la Facultad de Ciencias Exactas, pero advirtió que en caso de dar un comunicado, puntualizaria también que en su opinión la Universidad no habia contribuido, durante los últimos años, a formar el alma nacional, y había actuado bajo la influencia de grupos sectarios liberales o marxistas. ${ }^{2}$

Días más tarde, el diario Clarín difundió el anteproyecto de declaración "La CGT ante el proyecto universitario". ${ }^{3}$ El documento valoraba el nivel científico alcanzado por la universidad, negándose a concebirla como una isla. Pero al mismo tiempo condenaba las luchas que no hacían a su contenido concreto, no admitiendo la lucha "formal" por la autonomía. Finalmente, se exhortaba a la universidad a ser la palanca del cambio, "debe incorporarse a la revolución y no segregarse" sentenciaba.

Este documento devela que las palabras de Taccone, presente en el acto de asunción de Onganía (Anzorena, 1998: 16), no hacian otra cosa que intentar encubrir el compromiso de la dirección cegetista con la dictadura. Lejos de haber sido los años precedentes al golpe años de separación entre el movimiento obrero y el movimiento estudiantil, como retrataba Taccone, avanzada la década de 1960 las relaciones entre ambos sujetos se habian estrechado, siendo los estudiantes parte de los planes de lucha de la CGT bajo el gobierno de Illia (Califa, 2014 b). Así, por otro lado, lo expresaba un comunicado de apoyo a la

2. "Universitarios", Confirmado, 11 de agosto de 1966, año II, n 60, p. 11.

3. "La CGT analiza el problema universitario", Clarín, 16 de agosto de 1966, p. 20. Tanto en este diario como en otros me fue imposible dar con noticia alguna sobre la emisión definitiva de este documento. 
autonomía universitaria, firmado por unos cien dirigentes comunistas pertenecientes a una veintena de gremios, en el que decian: "Los trabajadores anhelan que la CGT [...] exprese su solidaridad militante. Así darian también reciprocidad a la activa solidaridad universitaria con las acciones proletarias de los últimos tiempos". ${ }^{4}$

Con todo, es verdad que la militancia universitaria de izquierda siempre había criticado a los "burócratas". Pero precisamente con esa categoría se distinguía a la base obrera de su dirigencia, en el afán de acompañar las luchas de los primeros, a pesar o más allá de las posturas de los últimos. ${ }^{5}$ Se insiste entonces en que la orientación política impresa por la dirigencia gremial al movimiento obrero resultó determinante para separar sus caminos. Tampoco los convenció la "expectativa esperanzada" que muchos trabajadores depositaron en el golpe. En definitiva, no era fundamentalmente un problema de "gorilismo", sino una divergencia respecto de la orientación política asumida frente al gobierno lo que bifurcó sus senderos.

En lo inmediato, el movimiento estudiantil opositor debió soportar una férrea represión en las facultades que incluyó golpizas, controles en los ingresos, policías de civil y uniforme deambulando en los pasillos y hasta soplones de parte de raquiticas organizaciones nacionalistasperonistas de derecha que siempre habian visto en el reformismo un enemigo. Estas luchas en todo el país alcanzaron su pico con el asesinato de parte de la policía de Santiago Pampillón en Córdoba durante septiembre de 1966 (Ferrero, 2009: 171). Sin embargo, la indignación que desató este hecho no impidió el declive de la conflictividad universitaria. Pese a este retroceso, la FUA, en manos de los comunistas, seguía sosteniendo que la dictadura estaba asentada sobre un "verdadero tembladeral" y que la lucha no cesaba de abrir nuevas perspectivas. ${ }^{6}$

Ese diagnóstico levó a muchos militantes universitarios a lanzarse desde octubre en apoyo de la huelga portuaria en Buenos Aires, asediada por una mentada racionalización que conllevaba despidos, rebajas salariales e incrementos de ritmos laborales. Como reflexionaría Primera Plana: "Los contactos entre obreros y estudiantes son un motivo de preocupación para los hombres del P. Ejecutivo. Saben positivamente que el éxito de la Policía Federal contra la Universidad se debió a que los

4. "Los trabajadores junto a estudiantes y profesores en defensa de la autonomía universitaria", 30 de agosto de 1966 (Archivo PCA).

5. Así, un líder estudiantil declaraba: "Nuestros contactos son al nivel de dirigentes intermedios y de las bases. No creemos en los grandes bonetes de la CGT" ("Universidad. Un año perdido", Primera Plana, 3 al 9 de enero de 1967, p. 24).

6. "Resistencia y lucha", 14 de octubre de 1966, p. 1. 
universitarios fueron los únicos en oponerse a la revolución de junio". ${ }^{7}$ Sin embargo, la huelga portuaria, al igual que la huelga ferroviaria y azucarera, fue crudamente reprimida. Con su derrota comenzarian a desmoronarse las ilusiones fuístas.

En ese marco, Onganía relevó a Salimei del Ministerio de Economía y puso en su lugar a Krieguer Vasena. Según Juan Carlos Portantiero: "Se trata del intento más decidido realizado hasta hoy por la fracción dominante en el nivel económico-social, para superar a su favor una situación de crisis orgánica y transformar ese predominio en hegemonia" (1973: 85). Cuando el 10 de marzo de 1967, ante un gobierno envalentonado, la cúpula de la CGT resolvió abandonar el plan de lucha lanzado en diciembre pasado, aceptando la tregua propuesta por el Ministerio de Trabajo (De Riz, 2000: 58), el diagnóstico fuista cayó definitivamente en el anacronismo. Para entonces, la dirigencia estudiantil no pudo hacer otra cosa que criticar el "bochornoso levantamiento del plan de lucha".

La sanción el 21 de abril de 1967 de la "Ley Orgánica de las universidades" empeoró las cosas. La Ley 17.245 contenía ciento veintiséis artículos que regulaban detalladamente la vida académica. Si bien se establecía la autonomía académica, el artículo 71 la limitaba (Mignone, 1998: 48 y ss.). En relación al gobierno universitario, lo restringia a las cúpulas académicas. La nueva legislación admitía asimismo la existencia de centros estudiantiles sólo con fines recreativos. Por otro lado, obligaba a tomar exámenes de ingreso. Los artículos finales otorgaban un plazo de 120 días para adecuar los estatutos universitarios.

En ese contexto de avance de la dictadura y de inmovilismo social, la militancia de izquierda entró en un clima de reflexión. A mediados de 1967 el informe preparatorio de la Convención Nacional de Centros convocada por la FUA expresaba una crítica de las acciones de tipo "putchistas" desarrolladas tras el golpe: "Se impulsaron en algunos centros hechos políticos que se desligaron de la necesaria construcción del proceso estudiantil masivo que junto a la clase obrera y el pueblo, y sólo así, podrá hacer variar radicalmente la situación". ${ }^{9}$ Frente a la desilusión reinante, se produjeron escisiones que derivaron en nuevas formaciones politicas. Algunas habian surgido poco antes, aunque se terminaron de amoldar en ese interín, como los pro peronistas del FEN (Frente de Estudiantes Nacionales) (Reta, 2010) otras no se originaron como corolario de la discusión universitaria, pese a lo cual fueron influidas por esta atmósfera: la escisión del Partido Revolucionario de los Trabajadores lo ejemplifica (Mangiantini, 2015), mientras que la rup-

7. "Universidad. Un año perdido", Primera Plana, 3 al 9 de enero de 1967, p. 24.

8. "FUA", programa fechado en junio de 1967, p. 20.

9. "FUA", Junta Ejecutiva, junio de 1967, p. 26. 
tura del Partido Comunista que dominaba la FUA y era la fuerza más importante en la UBA, hecho que derivó más adelante en el PCR-FAUDI (Partido Comunista Revolucionario-Frente de Agrupaciones Universitarias de Izquierda) que se quedó con el manejo de la federación, resultó directamente impactada por la derrota universitaria (Califa, 2015).

\section{E1 retorno de la conflictividad social}

Durante 1968 el movimiento obrero comenzó a recuperar protagonismo. El surgimiento de la CGT de los Argentinos (CGTA), liderada por el gráfico Raimundo Ongaro, marcó la ruptura de la pax romana en el mundo laboral (Romero, 1994: 328). La CGTA postulaba una mayor confrontación con la dictadura, desafiando tanto a la posteriormente llamada Nueva Corriente de Opinión (Construcción, Luz y Fuerza, vitivinícolas, etc.), identificada con el participacionismo obsecuente con el gobierno, como a la tibieza de la CGT mayoritaria "dialoguista" capitaneada por Vandor (Dawyd, 2011). ${ }^{10}$ La nueva central propició formas de participación gremial menos jerárquicas y una gran apertura a los estudiantes (Gordillo, 2007: 345 y ss.).

La prensa de la CGTA hace observable los vínculos con los universitarios. En su primer número a comienzos de mayo de 1968 les decía: "Queremos verlos junto a nosotros [...] La CGT de los argentinos no les ofrece halagos ni complacencias, les ofrece una militancia concreta junto a sus hermanos trabajadores" ${ }^{11} \mathrm{El}$ cuarto número afirmaria: "La destrucción de la universidad, el éxodo de los profesores, el cierre de las aulas para los sectores más humildes, no hubieran sido posibles si un movimiento estudiantil organizado hubiera tenido el apoyo de un movimiento obrero organizado". ${ }^{12}$ Ese entrelazamiento que buscó le valió el apodo peyorativo de "CGT de los estudiantes" por parte de la central sindical rival.

Las agrupaciones estudiantiles peronistas, todas marginales a

10. Coincido con la caracterización de Alejandro Schneider: "En materia de proyectos, la entidad liderada por Ongaro se planteaba como objetivos el derrocamiento del gobierno militar, junto con una serie de medidas que determinados analistas han estimado como de transición al socialismo. En realidad, se acercaba más a las propuestas sostenidas por los sectores combativos del peronismo. En ese sentido, sus postulados no fueron más allá de una simple reafirmación de los programas sindicales dictados por los plenarios gremiales de La Falda (1957) y Huerta Grande (1962), teñidos con experiencias religiosas y citas evangélicas" (Schneider, 2005: 291). 11. "10 de mayo: mensaje a los trabajadores y al pueblo argentino", CGT. Órgano Oficial de la Confederación General de Trabajo, 1 de mayo de 1968, año 1, nº 1, p. 1. 12. "Las calles son del pueblo, CGT. Órgano Oficial de la Confederación General de Trabajo, 23 de mayo de 1968, año 1, no 4, p. 1 . 
excepción del FEN, resultaron las más beneficiadas por esta relación sindical. ${ }^{13}$ Estos grupos, a diferencia de la izquierda no peronista, conseguirian una presencia más orgánica en la nueva central. Los militantes de la TERS (Tendencia Estudiantil Revolucionaria Socialista), brazo estudiantil del trotskista Politica Obrera, aclaraban que "las comisiones obrero-estudiantiles que creó la CGT sólo sirven para que los caudillitos del FA las instrumenten a favor del frente burgués", esto es, el frente que conducia el FEN en Filosofia y Letras. ${ }^{14}$ Frente a este tipo de acusaciones, que eran lugar común entre la izquierda ajena al peronismo, dicha organización se defendía:

Así, ARFYL, UAP, MR8, TERS, etc. [grupos de izquierda no peronista en Filosofia y Letras] no llaman a la CGT 'de los argentinos' por temor a ser confundidos con agentes de la burocracia sindical e hibridan su apoyo, y más que su apoyo (lo definitorio para el movimiento estudiantil), retacean la acción unida de los estudiantes de Filosofia y Letras contra los trabajadores argentinos, por la falta de ortodoxia revolucionaria de la actual dirección revolucionaria de la CGT de los argentinos. ${ }^{15}$

Otro grupo trotskista, el brazo universitario del PRT "La Verdad", señalaba en un volante que el 3 de junio una concentración de 50 personas de diversos grupos de izquierda, entre los que se encontraba la mayoritaria dirección de la FUA, quiso hacerse escuchar en las puertas de la CGTA. ${ }^{16}$ Pero lo que recibieron fueron saludos provocadores de los

13. Una declaración firmada por grupos peronistas de todo el país mostraba el apoyo en la UBA de FANDEP, MND (Derecho), CEA (Derecho), LAN (Filosofia y Letras), ALUL (Filosofia y Letras y Ciencias Exactas y Naturales), UNEFYL (Filosofia y Letras), FEN, FA (Filosofia y Letras), EA (Filosofia y Letras), MHR (Filosofia y Letras), FAN (Filosofia y Letras), Liga Humanista (Ciencias Exactas y Naturales, Ingenieria y Ciencias Económicas, adheridas a UNE), CAENI (Ingenieria), TUPAU (Arquitectura), MUN (Arquitectura), RR (Ciencias Económicas), ARCE (Ciencias Económicas), MUN (Ciencias Económicas), VUMM (Ciencias Exactas y Naturales). "El Movimiento Estudiantil Nacional y popular y revolucionario frente a la intervención y la dictadura junto a la CGT de los Argentinos", 11 de agosto de 1968, Rosario.

14. "Tendencia estudiantil revolucionaria. Un programa antidictatorial y antiimperialista para el movimiento estudiantil", junio de 1968, p. 7 (Archivo del Centro de Estudios Nacionales, Biblioteca Nacional, caja 18).

15. "La trayectoria y la auténtica política del frente antimperialista", FA, junio de 1968, p. 2 (Archivo del Centro de Estudios Nacionales, Biblioteca Nacional, caja 18). 16. "Idilio prestado: Ongaro rechazó los amores de la FUA, UPE de Farmacia y TERS", firmado por UAP (Filosofia y Letras), FELNA FAA (Ciencias Exactas y Naturales), ARE Avanzada (Ciencias Económicas y Derecho) (Archivo del Centro de Estudios Nacionales, Biblioteca Nacional, caja 18). 
militantes del FEN, que a diferencia de estos otros entraban sin problemas. Si bien es cierto que la central sindical brindó un recibimiento generoso a los estudiantes que viraban hacia el peronismo, lo cual pude ratificar leyendo su prensa, esa misma fuente hace observable que no por ello perdió de vista el arco estudiantil más amplio expresado en la militancia identificada con la Reforma de 1918. El avance de la conflictividad social, como se verá, haría más necesaria la alianza con las tendencias de izquierda no peronistas, con más incidencia en el conjunto del alumnado.

En paralelo, la UBA comenzaba a registrar cambios. En febrero de 1968 Raúl Devoto fue designado nuevo rector interventor. Se trataba de un médico hematólogo que desde mediados del año anterior se encontraba al frente de la Universidad Nacional del Nordeste. Su designación respondía a los anhelos de modernización que se trazaba el Ejecutivo, en tanto su antecesor era juzgado inútil para esa tarea (Mendonça, 2014: 37 y ss.). El 1 de abril de 1968 su gestión, en consonancia con la ley universitaria vigente, aprobó el nuevo estatuto de la UBA. En lo relativo a la organización universitaria preveía la estructura tradicional compuesta por asamblea universitaria, consejo superior, rector, decanos de facultades y consejos académicos, sin voto estudiantil.

Entre mayo y junio de 1968 la conflictividad universitaria se intensificó. El 9 de mayo se produjeron manifestaciones relámpago en Buenos Aires tras una frustrada entrevista con Devoto, en la que los jóvenes opositores criticaron las normas de promoción y regularidad. ${ }^{17}$ Una semana más tarde las protestas se trasladaron a Filosofia y Letras, Arquitectura y Económicas. ${ }^{18}$ Todas resultaron fuertemente reprimidas, siendo detenido el presidente de la FUA, Jacobo Tieffemberg, del FAUDI. Su encarcelamiento motivó el pedido de la CGTA por su liberación y su propuesta de que, de ahora en adelante, en cada actividad estudiantil hubiera una delegación de apoyo obrera y viceversa. ${ }^{19}$

Esa unidad de acción se concretaría a fines de junio. Ya a mediados del mes la FUA había conmemorado con una huelga, apoyado por esta central, el cincuentenario de la Reforma Universitaria. La jornada de protesta había concluido con 70 apresados, casi la mitad detenidos en la Capital Federal. ${ }^{20}$ Tres días después, la CGTA les ofreció la oportunidad de manifestarse mancomunadamente ante el segundo aniversario del golpe. A las consignas laborales con las que se convocó al acto en

17. BDB, sección mayo de 1968, p. 3.

18. BDB, sección mayo de 1968, p. 4 y ss.

19. “Junio: movilización popular”, CGT. Órgano Oficial de la Confederación General de Trabajo, 6 de junio de 1968, año 1, nº 6, pp. 1 y 3.

20. BDB, sección junio de 1968, p. 9. 
Plaza Once se agregó un enérgico repudio a la represión estudiantil. La FUA adhirió al mismo sumando los reclamos contra los estatutos, la ley universitaria, los aranceles y la política limitacionista. Sin embargo, los militantes del FAUDI no dejaban de criticar a Ongaro porque "cerraba el camino a la alternativa revolucionaria" y por sus vaivenes en tanto primero "boicoteó el paro universitario del día 14 para finalmente respaldarlo". ${ }^{21}$

El 28 de junio se sucedieron actos relámpago con fuerte presencia estudiantil, peronista y de izquierda. El gobierno desplegó 4.000 miembros de los aparatos represivos. Los incidentes se repitieron a lo largo de la jornada mostrando una inusual unidad obrero estudiantil. Así, por ejemplo, en la esquina de Independencia y Rioja cerca de las 8 de la noche, estudiantes de Filosofia y Letras, Ciencias Económicas y FEN, se concentraron junto a trabajadores de la Unión Ferroviaria, chocando con la policía. En paralelo, una columna de trabajadores y estudiantes avanzó desde el Mercado de Abasto, siendo reprimida en Plaza Once. ${ }^{22}$

A pesar del embate opositor, el Ejecutivo evitó lo que se vivía en países como Francia, México y Uruguay. Pero sería erróneo colegir de ello un retornó a la apatía política. La tranquilidad que la dictadura se encargó de trasmitir era engañosa (Potash, 1994: 65). Incluso en Buenos Aires, donde la calma era mayor que en otras ciudades, tuvieron lugar protestas durante lo que restaba de 1968 que no avalaban tal optimismo. Esta situación hizo que un cronista de Primera Plana se burlara de la paz que el ministro del Interior Guillermo Borda advertía en la Argentina frente a los disturbios estudiantiles mundiales: "Acaso lo único que el país desconocía era su sentido del humor, su capacidad irónica". ${ }^{23}$

En mayo de 1969 el optimismo oficial se derrumbó. Corrientes y Chaco a mediados de ese mes, unos dias después Rosario y finalmente Córdoba mostraron una potente movilización obrero-estudiantil (Millán, 2013).Una crónica periodística señalaba que esta alianza entre gremialistas y estudiantes era primicia mundial. ${ }^{24} \mathrm{Si}$ bien las marchas se iniciaron por demandas puntuales (la suba de los precios del comedor universitario en Corrientes o las peticiones por la reposición del sábado inglés en Córdoba, por ejemplo), rápidamente se impuso el cuestionamiento al dominio de la dictadura. ¿Qué pasó en la Capital Federal?

Al día siguiente del asesinato en Corrientes por parte de la policía

21. "Informe del Comité Nacional", Comité Nacional de Recuperación Revolucionaria, p. 4 y ss.

22. BDB, sección junio de 1968, p. 19 y ss.

23. "Universidad: el grito en la noche", Primera Plana, 18 al 24 de junio de 1968, p. 13. 24. "Estudiantes. La revuelta que supimos conseguir", Confirmado, 29 de mayo al 5 de abril de 1969, pp. 22-23. 
del estudiante Juan José Cabral, el 15 de mayo de 1969, en la UBA se registraron fuertes turbulencias. En Económicas tuvo lugar una concentración en el patio de la facultad en repudio al hecho. En Derecho se produjeron forcejeos y golpes entre un alumno y un docente que sostenia que Cabral "bien muerto estaba por comunista". Los mayores altercados se dieron en Filosofia y Letras en la noche del 16 de mayo cuando un tumulto estudiantil en su entrada resultó dispersado por la policía con gases, deteniendo a trece alumnos. ${ }^{25}$

E1 21 de mayo, tras dias de incidentes, tuvo lugar el paro nacional convocado por la FUA. En la UBA el acatamiento fue parcial. En Farmacia y Bioquímica se generaron desórdenes. En Ciencias Exactas y Naturales los fuístas ocuparon sus instalaciones, siendo violentamente desalojados por la policía. ${ }^{26}$ En todos los casos, la vigorosa presencia policial abortó las protestas. El 23 de mayo se produjo un paro nacional decretado por ambas CGT. En esa jornada tuvieron lugar numerosos incidentes entre la policía y los estudiantes en el centro porteño que pusieron en evidencia la intensa conflictividad social imperante. Los 71 universitarios apresados que arrojó la jornada así lo testimoniaban. ${ }^{27}$

Sin embargo, en los días posteriores una tensa calma invadió Buenos Aires. El movimiento laboral local, que había insinuado romper con su parálisis, finalmente se mantuvo impertérrito. Del mismo modo decayó la protesta estudiantil. En desmedro, el foco de la conflictividad se consolidaba en el centro del país. De Rosario se había trasladado a Córdoba, donde obreros y estudiantes protagonizaron a partir del 29 de mayo uno de los mayores levantamientos urbanos de la Argentina. Mientras tanto en la Capital Federal, durante esa jornada, la FUA organizó una marcha frente a la fábrica Alpargatas, siendo los pocos asistentes disueltos por la policía. ${ }^{28} \mathrm{~A}$ la tarde, el fuerte operativo de esta fuerza disuadió a la CGTA de realizar el acto programado en Plaza Once.

A mediados de junio de 1969 Onganía aceptó la renuncia de su gabinete. Sus reemplazantes fueron encabezados por el general Francisco Imaz, hasta entonces gobernador de la Provincia de Buenos Aires. Al frente de la secretaría de Educación y Cultura fue designado el rector de la Universidad Nacional de Cuyo, Dardo Pérez Guilhou. Esta casa de estudios, que habia pasado sin sobresaltos el temporal universitario, era la única que había avanzado en las disposiciones que fijaba la ley universitaria de cara a la "normalización". Se esperaba del ministro que

25. BDB, sección mayo de 1969, p. 15 y ss.

26. Esta información de acuerdo a "Universidad: hora de violencia", Panorama, 27 de mayo al 2 de junio de 1969, pp. 11-17.

27. BDB, sección mayo de 1969, p. 64 y ss.

28. BDB, sección mayo de 1969, p. 79. 
iniciara un diálogo con los universitarios opositores, permitiendo al gobierno frenar la ascendente influencia que ejercían los más belicosos. ${ }^{29}$

A fines de junio de 1969, en vísperas de la llegada de Nelson Rockfeller, magnate y gobernador de Nueva York, las protestas se reanudaron. La oposición veía su visita como una provocación gubernamental que se sobreimprimía al clima de beligerancia existente. ${ }^{30} \mathrm{El}$ Partido Comunista pergeñó un atentado que voló por los aires catorce supermercados Minimax, propiedad de la familia Rockefeller (Gilbert,1994: 268). Por su parte, la militancia juvenil de la UBA, con epicentros en Filosofia y Letras y Económicas, viviría una semana ajetreada.

Los incidentes alcanzaron su cenit el viernes 27 de junio, fecha en que la CGTA había dispuesto un nuevo paro general. El acto principal en Plaza Once fue dispersado por una cruenta represión. Víctima de esta, caería asesinado el militante de izquierda y ex secretario general del gremio de prensa Emilio Jáuregui. Según Primera Plana, "sólo hubo universitarios". ${ }^{31}$ Más allá de la exageración, el protagonismo estudiantil era evidente. El 30 de junio, horas después del asesinato del líder de la CGT, Vandor, los principales sindicatos de la CGTA fueron intervenidos, siendo Ongaro encarcelado. Frente a este panorama, la FUA no podía hacer otra cosa que depositar sus esperanzas en la "unidad por abajo" con el movimiento obrero. ${ }^{32}$ Pero, ¿tenía futuro? ¿Podrian estos universitarios pasar por encima de la dirigencia sindical? ¿La base obrera estaba esperándolos?

\section{De los dichos a los hechos en los primeros 70: la muralla sindical}

La militancia universitaria porteña tendió a acompañar el ascenso obrero concediéndole un lugar cada vez más destacado en su propaganda. A pesar de ello, la unidad en la lucha fue atípica en Buenos Aires. No es extraño que el FAUDI, al frente de la FUA, señalara que la vinculación con el movimiento obrero se podía ver en "el Cordobazo y el Rosariazo, en Pedriel y en Chocón", pero no podía dar un ejemplo similar para la

29. "Universidad. La hora de la sensatez", Confirmado, 19 al 25 de junio de 1969, p. 21. 30. Natalia Vega (2011) estudió las protestas que desató el arribo de Rockefeller a la Argentina, enfocándose en lo sucedido en la ciudad de Santa Fe, mientras que Gregorio Selser (1971) mostró las confrontaciones que su visita provocó en Latinoamérica. 31. "Las variaciones del tiempo borrascoso", Primera Plana, 1 al 7 de julio de 1969, p. 12 .

32. "Noveno Congreso de FUA. Resoluciones", FUA, diciembre de 1969 (Archivo del CEN, caja 19). 
Capital Federal y sus alrededores. ${ }^{33}$ Una "Carta abierta de la Junta Ejecutiva de la F.U.A. a la CGT de los Argentinos" le recriminaría a la CGTA que "lamentablemente, mientras en el Chocón obreros y estudiantes enfrentaban unidos a la dictadura y la policía estrechando en la práctica los lazos de combate, en la reunión de Paraná se impide la entrada a la Federación Universitaria Argentina". ${ }^{34}$ Tras acusar al reformismo de Ongaro y los suyos, propiciaban la conformación de una Mesa de Lucha integrada por los sectores combativos del movimiento obrero, el movimiento de Sacerdotes para el Tercer Mundo y el movimiento estudiantil. Proponían, en conmemoración del Cordobazo, coordinar un paro de 36 horas y una jornada antidictatorial y antiparticipacionista para el 29 de mayo.

No obstante, estos regaños y propuestas en Buenos Aires quedarian en un segundo plano dado el languidecimiento de la CGTA. En cambio, sus rivales de la CGT habian conseguido abroquelar, en alianza con la dictadura, al sindicalismo reacio a la izquierda, dejando de lado sus diferencias y enfatizando su identidad peronista y su verticalismo respecto al propio Perón (Pozzi y Schneider, 2000: 61). Incluso, contaron con el aporte de dirigentes de la CGT rebelde que, acordando con los deseos de Perón, retornaron al núcleo madre (Anzorena, 1998: 46). Esta unidad se había concretado con la realización de su congreso normalizador, paradójicamente a un año del Cordobazo, el día que la FUA había propuesto una acción de lucha al movimiento obrero.

Daniel James ha señalado que la "rebelión de las bases" de comienzos de la década de 1970 fue un producto del interior del país (1999: 302). Alejandro Schneider lo ha criticado por soslayar la presencia de nuevos cuerpos de delegados y comisiones internas en el área metropolitana (2005: 314). Un estudio de caso de lo acaecido en la fábrica Peugeot de Berazategui, por ejemplo, muestra la aparición de una renovada dirigencia obrera que atacó la burocracia y en ese proceso de lucha se ligó al activismo universitario (Carrera, 2010: 81). Seguramente nuevos estudios de caso podrian constatar más extensamente este fenómeno. Sin embargo, la inexistencia en la región metropolitana de una movilización de masas callejera emergente de las fábricas como en otras partes del país, quizás por lo prematuro aquí de este proceso antiburocrático, no creó condiciones propicias para un acercamiento más orgánico con los estudiantes.

Entre las parciales excepciones a esta constante se encuentran los paros generales convocados por la CGT. El 9 de octubre de 1970 se

33. "Ante el Congreso Nacional de Estudiantes convocado por la FUA", 5 de diciembre de 1970 , p. 1.

34. Ibidem. 
produjo una huelga contra la política económica vigente, provocándole una primera crisis al novel gobierno de Roberto Levingston. Ante ella, dado el respaldo de la militancia estudiantil de izquierda, el rector de la UBA resolvió el cese de actividades. ${ }^{35} \mathrm{El} 22$ de octubre prosiguió el plan de lucha cegetista con un nuevo paro, esta vez desde las 14 horas. En esa jornada, se generaron incidentes en Tucumán, Santa Fe, La Plata y la Capital Federal. En la UBA, la suspensión de actividades fue total. Según La Nación:

Hubo algunos incidentes entre sectores antagónicos cuando un grupo de bancarios y estudiantes arribó al lugar y gritó "Unidad, unidad". Esa actitud originó una gresca con otros grupos que daba vítores a Perón. El incidente duró algunos minutos, pero la policía no intervino. Hubo algunos heridos y contusos, no identificados. ${ }^{36}$

El diario daba cuenta de que los incidentes se iniciaron en las escalinatas de Ingeniería a las 15.15 horas, sita enfrente del local central de la CGT de la calle Azopardo donde debía realizarse el acto central. La crónica agregaba que el sector que se identificaba con tendencias de izquierda fue agredido a palos por columnas de los gremios de mecánicos y metalúrgicos. Pese a que la policía no intervino, sí lo hizo el resto de la jornada deteniendo a 253 trabajadores. En el discurso del acto central el secretario general de la CGT, José Ignacio Rucci, exclamó: "Vayan sabiendo quienes están acostumbrados a usar la palabra unidad como un manto piadoso para esconder sus asquerosas intenciones, que estamos perfectamente en claro que este movimiento obrero es auténticamente nacional y se hará respetar en cualquier terreno". ${ }^{37}$ Este acontecimiento era la contracara de las jornadas de unidad obrera-estudiantil de un año atrás.

En noviembre, una fuerte disputa salarial de los trabajadores no docentes universitarios ganaría protagonismo. En Buenos Aires, APUBA (Asociación del Personal de la Universidad de Buenos Aires) llevaría adelante el conflicto que implicaba a unos 8.000 trabajadores, aunque también varios docentes auxiliares con reclamos propios. Sin demora, los centros se plegaron al paro. Así, por ejemplo, en Ciencias Exactas y Naturales unos 100 estudiantes se congregaron el día 2 de ese mes frente al pabellón I de la Ciudad Universitaria, marchando desde allí a la

35. BDB, sección octubre de 1970, p. 2.

36. "El anunciado cese de tareas se realizó ayer", en La Nación, 23 de octubre de 1970, p. 6.

37. Idem, p. 10. 
sede céntrica de la facultad al canto de "Obreros y estudiantes, unidos y adelante". ${ }^{38} \mathrm{Al}$ día siguiente se reunieron los presidentes de los centros de Medicina, Arquitectura y Urbanismo, Química, Derecho e Ingeniería Tecnológica (UTN), declarando en estado de alerta al estudiantado porteño ante el cierre universitario. Además, expresaron su solidaridad con los trabajadores y resolvieron concentrase frente a Medicina. ${ }^{39}$

En los días siguientes la conflictividad ascendió, empalmando el 12 y 13 de noviembre con el paro cegetista de 36 horas. Sin embargo, a mediados de mes, cuando parecía que la lucha iba a dar un nuevo salto, se frenó. Según Primera Plana: "Los no docentes percibirán 12.000 pesos a cuenta hasta el 21 de diciembre y entonces serán escalafonados: se les pagarán los veinte días de huelga. Los docentes auxiliares recuperarán el índice 805 de Estatuto del Docente". ${ }^{40}$ Entre otras cuestiones, a la dirigencia sindical le preocupaba que el conflicto se convirtiera en una lucha que sobrepasara las reivindicaciones económicas con que había sido convocado. ${ }^{41}$ Los grupos de izquierda estudiantil que los apoyaban, razonaban los sindicalistas, podian conducirlos a una disputa politica más de fondo con la dictadura. Una fugaz reactivación del conflicto durante 1971 convirtió estos resquemores en enfrentamientos fisicos. Los mismos tuvieron lugar el 4 de marzo cuando la asamblea de APUBA desarrollada en el salón de actos de Derecho levantó el paro dispuesto tres dias antes. Un grupo de estudiantes, descontentos, mocionó por continuarlo frente a lo cual los dirigentes sindicales fueron a desalojarlos, produciéndose una trifulca. ${ }^{42}$ Otra vez, en una escala menor, los hechos daban cuenta de la falta de aliados sindicales del movimiento estudiantil radicalizado.

Esas agrias experiencias para la militancia estudiantil de la UBA enterraron definitivamente los anhelos de una lucha común en gran escala con el movimiento obrero local, como sucedió en otras ciudades del país. Si bien entre los grupos estudiantiles nunca se dejó de insistir en la centralidad de las luchas obreras, bajo el gobierno de Alejandro Lanusse, tercer mandatario de la declinante "Revolución Argentina", no hubo ocasiones locales para movilizar masivamente a los universitarios

38. BDB, sección noviembre de 1970, p. 2.

39. BDB, sección noviembre de 1970, p. 3 y “Universidad. Todos contra todos", Primera Plana, 10 de noviembre de 1970, p. 17.

40. "Universidad. La comezón de fin de curso", Primera Plana, 17 de noviembre de 1970, p. 20.

41. "Universidad. A puertas cerradas un diálogo imposible", Panorama, 17 al 23 de noviembre, p. 17.

42. BDB, sección marzo de 1971, p. 8. 
junto a los trabajadores. ${ }^{43}$ La inflación del 58,5\% de 1972, con la consiguiente caída del poder adquisitivo que produjo (Cordone, 1999: 65), no fue un aliciente para la movilización popular a gran escala en la región metropolitana. La política, expectante por la salida electoral de la dictadura que se abría, primó sobre la economía. Marcelo Cavarozzi (2002: 42) ha señalado que entre 1971 y 1973 se debilitó así la autonomía de las contestaciones celulares de carácter antiautoritario.Esta aserción general pinta una imagen precisa a la hora de observar lo sucedido en Buenos Aires con las luchas obreras independientes de la burocracia cuya continuidad fue cada vez más tortuosa. No obstante, no debe llevar a pensar que en la Universidad advino la calma. Por el contrario, en estos años los universitarios porteños, al igual que sus pares del resto del país, se encontraron entre las mayores preocupaciones del gobierno. Los reclamos corporativos tendieron a ganar centralidad en sus filas, convirtiéndose en un verdadero tembladeral para la dictadura. De entre todas las reivindicaciones, la que más impactó y unificó el accionar estudiantil fue la relativa al ingreso universitario, que como un corolario de las luchas logró ampliarse (en Buenos Aires estas luchas han sido analizadas por Seia, 2014). Fueron los comunistas quienes mejor pudieron capitalizar este clima de contestación, recuperando protagonismo tras su escisión partidaria. ${ }^{44}$ En cambio el FAUDI, desgajado de ese partido, al igual que los peronistas del FEN, los más fuertes entre esa corriente, perdieron peso entre los estudiantes.

\section{Conclusiones}

El 28 de junio de 1972 se adoptaron medidas especiales para impedir

43. Natalia Duval (2013: 45) narra los siguientes hitos en el acercamiento de la CGT al gobierno en paralelo que se desarrollaba una férrea persecución a los gremialistas opositores: designación del Ministro de Trabajo Rubén San Sebastián sugerido por su cúpula sindical, anulación de causas judiciales que pesaban sobre sus líderes, nuevos fondos gremiales a partir de descuentos compulsivos a los trabajadores y reglamentación de la Ley de Obras Sociales por la cual estos sindicalistas pasaron a manejar sumas millonarias.

44. A fines de 1970 un documento de la Federación Juvenil Comunista expresaba nítidamente esta política: "El camino de la lucha actual en las universidades, a partir de la acción reivindicativa inmediata, es la brega por establecer de hecho, consolidar y ampliar la aplicación y adecuación de los postulados de la Reforma Universitaria mediante la acción unitaria de los estudiantes, graduados y docentes, derrotando a la política de la dictadura y vinculando este accionar al de todo el pueblo por su derrocamiento, la instauración de un gobierno verdaderamente democrático y popular y contribuir así a la lucha por cambios profundos en la realidad universitaria y económica-social del país", Hacia el IX Congreso de la Federación Juvenil Comunista (Archivo PCA). 
los actos programados por las Juventudes Políticas, una coalición donde sobresalían peronistas, radicales y comunistas. El centro del conflicto estaba en Buenos Aires, donde se temía un "porteñazo". Unos 3.000 efectivos de la Policía Federal rodearon 272 manzanas. La UBA decretó asueto para evitar concentraciones. Al atardecer una columna ingresó a Plaza de Mayo bajo el lema "Unamos nuestras manos por el argentinazo". Le siguieron varios intentos de movilización en las cercanías. Una manifestación de aproximadamente 2.000 estudiantes en el barrio de San Telmo levantó barricadas y chocó con la policia, que arrojó gases y detuvo a 150 de ellos. Poco después esta fuerza ingresó a la Facultad de Medicina, donde secuestró una bomba molotov y propaganda "terrorista". La jornada finalizó con 262 presos. ${ }^{45}$

La protesta marcó el ocaso de la movilización más radical del período. En relación a la cuestión de la unidad obrero-estudiantil, se podría pensar que concluyó la dictadura tal cual se inició: los estudiantes y los trabajadores deambulando senderos diferentes. Como se mostró en el artículo, el gobierno de Lanusse no encontró en la Capital Federal una fuerza social de composición obrero-estudiantil desafiante al igual que en otras ciudades de la Argentina. El "porteñazo" nunca llegó.

Sin embargo, sería erróneo colegir de ello que durante la "Revolución Argentina" nada varió en Buenos Aires. Como se vio, entre los grupos estudiantiles opositores a la dictadura la cuestión obrera se consolidó como un problema central. Por otro lado, las experiencias sindicales que se desarrollaron por fuera del tronco de la CGT tendieron a otorgarles igual centralidad a los jóvenes universitarios. Así, la CGTA llegó a reconocer sin ambages en su prensa que el sindicalismo se había equivocado al darle la espalda a los universitarios. Para los dirigentes de esta central, el movimiento estudiantil constituía un aliado fundamental.

¿Por que esta unidad no prosperó? Como es sabido, arrancado 1970 la CGTA pasó al ostracismo. Fue entonces cuando aparecieron otras experiencias de lucha obrera, más a su izquierda, que se suelen identificar con el clasismo. Una de las más célebres al respecto fue el SitracSitram cordobés. Estas experiencias, empero, no tuvieron en principio el mismo peso en Buenos Aires y sus alrededores. Habría que esperar a mediados de la década para que surjan las coordinadoras interfabriles que mostraron una maduración de esta corriente obrera en la región metropolitana. Mientras tanto la vieja dirigencia sindical peronista pudo hacer gala aquí de un mayor arraigo. Incluso posteriormente la tendencia del peronismo universitario -en tanto fenómeno de masas, un producto de la coyuntura de 1973, por el hecho de compartir una misma identidad 
política general con muchos sindicalistas- no encontraría más factible esa unidad, sino todo lo contrario.

En ese sentido, en este artículo se han puesto en entredicho los discursos académicos y políticos que tienden a pensar la falta de unidad obrero-estudiantil como un déficit de los segundos frente a los primeros, derivado de sus concepciones políticas ajenas al peronismo. El trabajo empírico demuestra la endeblez de este tipo de aseveraciones. Si la unidad entre el movimiento obrero y el movimiento estudiantil no fue posible, su causa es necesario buscarla más en el primero que en el segundo sujeto. La dirigencia sindical peronista dominante, una vez dejada atrás la breve experiencia de la CGTA en Buenos Aires, pese a los diferentes grupos que componían al estudiantado, repudió esta unidad dada su orientación política radicalizada general, vivida como una amenaza.

En definitiva, la respuesta al interrogante acerca del desarrollo efectivo de la unidad obrero-estudiantil no puede realizarse en abstracto, por fuera del conocimiento básico del periodo indagado. En ese sentido, aquí se realizaron dos señalamientos metodológicos: en primer lugar, la centralidad puesta en los enfrentamientos sociales, para observar, más allá de los anhelos expresados en los discursos sociales, cómo se desenvolvió la relación entre ambos sujetos. En segundo lugar, mostrar que tal indagación no es suficiente sin atender al mismo tiempo las orientaciones políticas que en cada momento primaban entre tal o cual sujeto. Así, el movimiento estudiantil porteño al atravesar los últimos años de la "Revolución Argentina" no encontró ni en el contexto general ni entre la dirección sindical un aliciente hacia la unidad, sino todo lo contrario. En este clima, si bien ninguna de las agrupaciones dejó de plantear la cuestión obrera como crucial en la lucha contra la dictadura, advirtió que frente al panorama reinante resultaba más fructífero, y casi la única opción efectiva, desarrollar las luchas reivindicativas universitarias al punto de conquistar una movilización que se constituyera en un desafio al gobierno. En esa estrategia se impuso el Partido Comunista, arrasando por ejemplo en las elecciones de centros estudiantiles de la UBA a fines de 1972, en desmedro de otros grupos portadores de un lenguaje más radicalizado.

Sin duda que estas dos premisas de trabajo, en base a la cuales se avanzó en el conocimiento de la problemática de la unidad obreroestudiantil, pueden ser revisitadas con una profundidad empírica mayor $\mathrm{y}$, asimismo, es plausible sumar otros criterios de observación. Este aporte ha consistido en ofrecer un conocimiento básico de la cuestión que permita aparatarse de discursos que confunden más de lo que clarifican, en pos de alcanzar un conocimiento acabado de la cuestión. 


\section{Bibliografia}

Anzorena, Oscar (1998), Tiempo de violencia y utopia. Del golpe de Onganía (1966) al golpe de Videla (1976), Buenos Aires: Colihue.

Barletta, Ana (2002), "Una izquierda universitaria peronista. Entre la demanda académica y la demanda política (1968-1973)", Prismas. Revista de Historia Intelectual, ${ }^{\circ}$ 6. Quilmes: UNQ, pp. 275-286.

Califa, Juan (2014a), Reforma y revolución. La radicalización politica del movimiento estudiantil de la UBA, 1943-1966, Buenos Aires: Eudeba.

- (2014b), "Hacia la unidad obrera estudiantil y el socialismo. El movimiento estudiantil de la Universidad de Buenos Aires frente a la clase obrera, 1955-1966", en Mariano Millán (comp.), Universidad, politica y movimiento estudiantil en Argentina (entre la "Revolución Libertadora" y la democracia del 83), Buenos Aires: Final Abierto, pp. 49-75.

- (2015), "Del Partido Comunista al Partido Comunista Comité Nacional de Recuperación Revolucionaria en la Argentina de los años sesenta. Una escisión con marca universitaria”, Revista Izquierdas, n² 24, julio, Santiago de Chile: USACH, pp. 173-204.

Carrera, Pablo (2010), La lucha obrera durante la "Revolución Argentina". Un estudio de caso: Fábrica Peugeot (1966-1973), Temperley: Flor de Ceibo.

Cavarozzi, Marcelo (2002), Autoritarismo y democracia, Buenos Aires: Eudeba.

Cordone, Héctor (1999), "Consideraciones acerca de la evolución de las relaciones laborales en la historia argentina reciente (1955-1983)", en Arturo Fernández y Raúl Bissio (comps.), Politica y relaciones laborales en la transición democrática argentina, Buenos Aires: Lumen, pp. 27-90.

Dawyd, Darío (2011), Sindicatos y politica. El Peronismo entre la CGT de los Argentinos y la reorganización sindical (1968-1970), Buenos Aires: Pueblo Heredero.

De Riz, Liliana (2000), La politica en suspenso 1966-1976, Buenos Aires: Paidós.

Díaz de Guijarro, Eduardo, Beatriz Baña, Carlos Borches y Raúl Carnota (2015), Historia de la Facultad de Ciencias Exactas y Naturales, Universidad de Buenos Aires, Buenos Aires: Eudeba.

Duval, Natalia (2013), Los sindicatos clasistas: Sitrac (1970-1971), Buenos Aires: Razón y Revolución.

Ferrero, Roberto (2009), Historia crítica del movimiento estudiantil de Córdoba, vol. III: 1955-1973, Córdoba: Alción.

Gilbert, Isidoro (1994), El oro de Moscú. La historia secreta de las relaciones argentino-soviéticas, Buenos Aires: Planeta.

Gordillo, Mónica (2007), "Protesta, rebelión y movilización: de la resistencia a la lucha armada, 1955-1976", en Daniel James (dir.), Nueva historia argentina. Violencia, proscripción y autoritarismo (1955-1976), vol. IX, Buenos Aires: Sudamericana, pp. 329-380.

Graciarena, Jorge (1971), "Clases medias y movimiento estudiantil. El Re- 
formismo Argentino: 1918-1966", Revista Mexicana de Sociología, año 3, $\mathrm{n}^{\circ} 1$, enero-marzo, México DF: Instituto de Investigaciones Sociológicas UNAM, pp. 61-100.

James, Daniel (1999), Resistencia e integración. El peronismo y la clase trabajadora argentina, 1946-1976, Buenos Aires: Sudamericana.

Mangiantini, Martín (2015), "PRT-La Verdad y el movimiento estudiantil argentino. Hacia un análisis de las estrategias de inserción y de las tensiones existentes (1968-1972)", Revista Izquierdas, n²3, abril, Santiago de Chile: USACH, pp. 81-101.

Mendonça, Mariana (2014), "Los (frustrados) intentos de modernización de la Universidad de Buenos Aires desde su creación hasta el rectorado de Devoto (1821-1968)", en Mariano Millán (comp.), Universidad, politica y movimiento estudiantil en Argentina (entre la "Revolución Libertadora" y la democracia del 83), Buenos Aires: Final Abierto, pp. 13-47.

Mignone, Emilio (1998), Política y universidad. El Estado legislador, Buenos Aires: Lugar Editorial.

Millán, Mariano (2013), Entre la universidad y la politica: los movimientos estudiantiles de Corrientes y Resistencia, Rosario, Córdoba y Tucumán durante la "Revolución Argentina", Buenos Aires: tesis de doctorado en Ciencias Sociales, Facultad de Ciencias Sociales, UBA.

Morero, Sergio, Ariel Eidelman y Guido Lichtman (1996), La Noche de los Bastones Largos 30 años después, Buenos Aires: Documentos Página 12.

O’Donnel, Guillermo (2009), El Estado burocrático autoritario, 1966-1973. Triunfos, derrotas y crisis, Buenos Aires: Prometeo.

Portantiero, Juan Carlos (1973), "Clases dominantes y crisis politica en la Argentina actual”, en Oscar Braun (comp.), El capitalismo argentino en crisis, Buenos Aires: Siglo Veintiuno, pp. 73-117.

Potash, Robert (1994), El ejército y la politica en la Argentina, 1962-1973. De la caída de Frondizi a la restauración peronista, Buenos Aires: Sudamericana.

Pozzi, Pablo y Alejandro Schneider (2000), Izquierda y clase obrera: 19691976, Buenos Aires: Eudeba.

Reta, Alejandra (2010), El proceso de peronización dentro del movimiento universitario en los años sesenta en Argentina. El caso de Frente Estudiantil Nacional, Buenos Aires: tesis de maestría en Investigación en Ciencias Sociales, Facultad de Ciencias Sociales,UBA.

Romero, Luis (1994), Breve historia contemporánea de la Argentina, Buenos Aires: Fondo de Cultura Económica.

Schneider, Alejandro (2005), Los compañeros. Trabajadores, izquierda y peronismo 1955-1973, Buenos Aires: Imago Mundi.

Seia, Guadalupe (2014), "La lucha del movimiento estudiantil por el ingreso directo: una aproximación al caso de la Universidad de Buenos Aires entre 1969 y 1973”, en Mariano Millán (comp.), Universidad, política y movimiento estudiantil en Argentina (entre la "Revolución Libertadora" y la democracia del 83), Buenos Aires: Final Abierto, pp. 77-107. 
Selser, Gregorio (1971), Los cuatro viajes de Cristóbal Rockefeller, Buenos Aires: Hernández.

- (1986), El onganiato, la espada y el hisopo, Buenos Aires: Hyspamérica. Vega, Natalia (2011), "Malvenido Mister Rockefeller. Acciones de protesta en 1969”, Rojo y Negro, año 2, n 2, Santa Fe: Centro de Documentación y Estudios Sociales, pp. 4-11.

Sigal, Silvia (1991), Intelectuales y poder en la década del sesenta, Buenos Aires: Puntosur.

Terán, Ocar (2013), Nuestros años sesenta: la formación de la nueva izquierda intelectual argentina, 1956-1966, Buenos Aires: Siglo Veintiuno.

$$
* * *
$$

Titulo: "Workers and students. States and forth?" Students of the University of Buenos Aires against the labor movement under the "Revolution Argentina", 1966-1976

Resumen: En este artículo se explora la relación entre el movimiento obrero y el movimiento estudiantil durante una etapa decisiva del auge de la conflictividad política como lo fueron las décadas de 1960 y 1970 en la Argentina. Más concretamente, se atenderá a esta relación en la ciudad de Buenos Aires, poniendo el foco en la militancia estudiantil de la Universidad de Buenos Aires durante el autoproclamado gobierno de la "Revolución Argentina". La perspectiva teórica elegida privilegia la observación de los enfrentamientos sociales en que ambos sujetos confluyeron. El texto se basa en diversas fuentes primarias y secundarias. Palabras clave: movimiento estudiantil - movimiento obrero - Buenos Aires "Revolución Argentina"

Abstract: This article explores the relationship between the labor movement and the student movement during a critical stage the rise of political conflicts as were the 1960s and 1970s in Argentina. More specifically, it will serve this relationship in the city of Buenos Aires, putting the focus on student activism at the University of Buenos Aires during the government of the self-proclaimed "Revolución Argentina". The theoretical perspective chosen privileges the observation of social confrontations in both subjects. The text is based on various primary and secondary sources.

Keywords: student movement - the labor movement - Buenos Aires - "Revolución Argentina"

Recepción: 15 de febrero de 2016. Aprobación: 15 de marzo de 2016 